\title{
Understanding of informed consent by parents of children enrolled in a genetic biobank
}

\author{
Jennifer Klima, $\mathrm{PhD}^{1,6}$, Sara M. Fitzgerald-Butt, MS², Kelly J. Kelleher, MD, MPH ${ }^{1,3,4}$, \\ Deena J. Chisolm, PhD ${ }^{1,3,4}$, R. Dawn Comstock, PhD ${ }^{4,5}$, Amy K. Ferketich, PhD ${ }^{4}$ \\ and Kim L. McBride, MD, MS',3
}

\begin{abstract}
Purpose: Prior research suggests that parents undervalue long-term risks associated with their children's participation in research studies. The primary aim of this study was to evaluate parental understanding of informed consent for a pediatric biobanking study.

Methods: The study population included parents who provided consent for their child to participate in a study examining the genetic etiology of congenital cardiovascular malformations. Informed consent understanding was measured by adapting the Quality of Informed Consent assessment to our study. We evaluated possible predictors of individual Quality of Informed Consent items using generalized estimating equations.
\end{abstract}

Results: A total of 252 individuals representing 188 families completed the study. The Quality of Informed Consent items best under-

\section{INTRODUCTION}

The policies governing the inclusion of children in genetic research with biorepositories are frequently debated, but there is little information on the quality and effectiveness of informed consent administration for current pediatric biobanking studies. The limited available research on parents as proxies for consent does not provide guidance on how best to administer informed consent in pediatric research, particularly in genetic epidemiologic research. ${ }^{1,2}$ In such research, parents must understand the rationale for tissue collection and storage, any physical or psychological risks that could result from tissue collection, the uncertainty around future unspecified studies on biospecimens, and how long biospecimens might be held for current or future research purposes. ${ }^{3-6}$ Principal among these new concerns about biobanking include the uncertainty about future testing and use of materials in long-term storage banks for children and adolescents, thereby precluding parents from making informed decisions about the risks and benefits of a study as required by the Common Rule. ${ }^{7-10}$ Prior research suggests that parents undervalue long-term risks in considering their children's participation in studies. ${ }^{11}$ When the risks associated with genetic studies and biobanking may be far off in the future and the specific studies are not clearly identified, this undervaluing may be exacerbated. stood by parents included consent to participate in research, the main purpose of the study, and the possibility of no direct benefit. The items least understood by parents were those involving the indefinite storage of DNA, the possible risks of participation, and the fact that the study was not intended to treat their child's heart defect. Parent age and medical decision making by one versus both parents were frequent predictors of individual Quality of Informed Consent items.

Conclusion: Parents overestimate personal benefit and underestimate the risks associated with their child's participation in a biobanking study.

Genet Med advance online publication 27 June 2013

Key Words: biobank; genetic research; informed consent; informed consent understanding; pediatric biobank

This study fills a gap in the current research on informed consent comprehension by examining parents who enrolled their children in a biobanking study. The Knowledge, Attitudes and Informed Consent study included parents whose children participated in a research study for children with congenital cardiovascular malformations (CVMs) of the left-ventricular outflow tract (LVOT). The primary aims of the current study were threefold: (i) to describe the overall parental understanding of informed consent, (ii) to reveal specific areas where there are deficits in understanding of informed consent, and (iii) to describe and compare differences in informed consent understanding by demographic characteristics. The long-term goal of this study is to pinpoint the deficits in parents' understanding of informed consent in order to inform best practices for improving informed consent administration.

\section{Study population}

\section{MATERIALS AND METHODS}

Participants in this study had participated in the informed consent process for the institutional review board-approved Genetics of Left Ventricular Outflow Tract (LVOT) Malformations study, hereafter called the LVOT study, at Nationwide Children's Hospital. The long-term goal of the

\footnotetext{
${ }^{1}$ Center for Innovation in Pediatric Practice, Nationwide Children's Hospital, Columbus, Ohio, USA; ${ }^{2}$ Center for Cardiovascular and Pulmonary Research, Nationwide Children's Hospital, Columbus, Ohio, USA; ${ }^{3}$ Department of Pediatrics, College of Medicine, The Ohio State University, Columbus, Ohio, USA; ${ }^{4}$ College of Public Health, The Ohio State University, Columbus, Ohio, USA; ${ }^{5}$ Center for Injury Research and Policy, Nationwide Children's Hospital, Columbus, Ohio, USA; ${ }^{2}$ Present address: OhioHealth Research and Innovations Institute, Columbus, Ohio, USA. Correspondence: Kim L. McBride (Kim.mcbride@nationwidechildrens.org) or Jennifer Klima (jklima2@ohiohealth.com)
} 
LVOT study was to identify the genetic etiology of LVOT congenital CVMs (including aortic valve stenosis, coarctation of the aorta, bicuspid aortic valve, hypoplastic left-heart syndrome, mitral valve stenosis, mitral valve atresia, Shone complex, and interrupted aortic arch type A). Eligible probands (index cases with an LVOT malformation) were identified from the cardiology clinic and/or inpatient records at Nationwide Children's Hospital. Participation in the LVOT study included the collection of medical and pregnancy history of the mother and family, a detailed pedigree (at least three generations), and permission to access the medical record prospectively. Permission was obtained to request medical records from outside the institution via a signed medical release. A blood, tissue, or saliva sample was obtained from the identified proband and, if possible, the parents and any additional relatives with a CVM. Individuals consented to storage of their biologic sample indefinitely for use in a variety of genetic analyses, including genotyping for association studies and sequencing, and for establishment of an immortalized cell line. Subjects could also opt in to allow anonymous sharing of their biologic sample with other investigators. In addition to standard HIPAA (Health Insurance Portability and Accountability Act) language, subjects were informed of the National Institutes of Health (NIH) policy for sharing of data obtained in NIH-supported or -conducted genome-wide association studies, which requires $\mathrm{NIH}$ funded investigators to share genotyping and sequencing results in the dbGAP database after deidentifying their data. The consent document stated that the investigators of the LVOT study also obtained a certificate of confidentiality from the NIH to further protect subjects.

\section{Inclusion/exclusion criteria}

This study included parents of probands who consented to participate in the LVOT study during the period 1 April 2004 through 1 April, 2008. Probands up to 20 years of age at the time of consent for the LVOT study, whose parents were also included in the consent process, were eligible. Families were deemed ineligible if there was no record of parent consent, the parent involved in the LVOT consent process was unavailable due to changes in custody, valid contact information could not be obtained, or the proband was deceased.

Eligible families were sent a letter introducing the study and were given the opportunity to decline participation by e-mail or phone. Survey packets were then mailed to all eligible families who did not decline to participate, and each parent or guardian in the household was asked to complete the surveys. Instructions were provided indicating respondents were not to assist each other with answering the questions. A \$3 cash incentive was included in the survey packet for participation in the study. If no response was received within 2 weeks, families were sent a second packet. If there was no response following the second mailing, families were given a follow-up call.

\section{Measuring informed consent understanding}

Understanding of informed consent was measured using the Quality of Informed Consent (QuIC) assessment, which has been validated in parents of pediatric cancer patients and biobank participants. ${ }^{12-14}$ This brief measure assesses understanding of the following domains: (i) the purpose of the research; (ii) the expected duration of participation; (iii) the procedures; (iv) the experimental procedures; (v) the foreseeable risks or discomforts; (vi) the benefits that may be reasonably expected; (vii) the appropriate alternative procedures or treatments; (viii) the confidentiality of research records/participant information; (ix) the compensation and the medical treatment provided if injury results; ( $\mathrm{x}$ ) whom to contact if the participant has questions about the study, participants' rights, or a research-related injury; and (xii) the voluntary nature of research, including the right to refuse participation or withdraw without any penalty or loss of benefits.

The QuIC assessment includes measures of both objective (how well individuals understand their clinical trial/study; part A) and subjective (how well informed participants believe themselves to be; part B) understanding. To reflect the unique procedures and risks in the LVOT study, the QuIC scales were modified to address the storage and future use of biospecimens for other research studies, the possible psychological risks associated with participating in the biobank, and the disclosure of results performed on the stored samples, both now and in the future (Tables 1 and 2). These questions were formulated with the genetic counselor (S.M.F.) and the principal investigator (K.L.M.) of the LVOT study.

Participants' responses to the questions on the QuIC assessment were assigned numerical scores. A total QuIC objective score was constructed by calculating the proportion of correct responses. Responses marked as unsure were treated as incorrect when calculating the total score.

The QuIC subjective subscale required respondents to indicate how well informed they believed themselves to be on a rating scale from 1 to 5 , where a rating of 1 indicates little to no understanding and a rating of 5 indicates very good understanding for each of 14 aspects of the study. The scores of these 14 items were averaged, resulting in a summary raw score that ranged from 1 to 5 .

\section{Statistical analysis}

The PROC GENMOD procedure in SAS 9.2 (SAS Institute, Cary, NC) was used to analyze all outcomes because it accounts for correlation by family to accurately derive estimates of effect when comparing QuIC scores across groups. Clustered data were analyzed by using the REPEATED statement in PROC GENMOD, which calls upon generalized estimating equations to model the outcomes of interest.

All knowledge scores from the QuIC objective subscale were compared on characteristics of interest by specifying a binary distribution in PROC GENMOD, resulting in Wald statistics with associated $P$ values. Results of the final model are presented as coefficient estimates, $z$-scores, and $P$ values, as well as the overall model $\chi^{2}$ score statistic for significant associations. To account for the multiple tests performed in this study, statistical significance was set at $P<0.01$. The QuIC subjective 


\section{Table 1 Responses to QuIC assessment part A}

Question

A1 When I signed the consent form(s) for this study, I knew that I was giving consent for myself and my child to participate in a research study

A2 The main purpose of this study is to find out how changes in genes might cause heart defects

A3 I was informed how long this study would last

A4 Leftover blood, saliva, or tissue samples that my child and I gave for this study can be used for other research studies, even if I did not give my permission

A5 The researchers in this study are interested specifically in heart defects called "left ventricular outflow tract" malformations

A6 One of the main purposes of this study is to find out how to treat my child for his/her heart defect

A7 The researchers in this study would like to compare family members to find out which genes may cause heart defects

A8 One of the goals of this study is to find out how many people in my family have heart defects

A9 As part of this research study, my DNA and my child's DNA will be stored for an indefinite period of time

A10 My child's participation in this study may help researchers treat him/her for heart defects

A11 In this study, I was asked to give information about my family's medical history

A12 The blood or saliva samples my child and I gave for this study will be stored indefinitely

A13 There are no risks of harm or discomfort to me or my child while participating in this study

A14 There may not be any direct benefit to me or my child while participating in this study

A15 It is possible that nonpaternity (no biological relationship between father and child) could be discovered in this study

A16 My family's participation in this study may help researchers understand how to prevent heart defects from happening in other children

A17 My family will receive the results of the genetic tests performed on the blood/saliva samples we provided for this study

A18 The anonymous results of the genetic tests performed on my family's blood/saliva samples will be made available to the National Institutes of Health $(\mathrm{NIH})$

A19 In this study, the identity of my family is protected from use in court proceedings by a Certificate of Confidentiality

A20 I was given information on who to contact if I have any questions about this study

A21 The consent form that I signed described who would pay for treatment if my child or I became injured or ill as a result of participation in this study

A22 Once I gave consent to be in this study, I could not withdraw my participation

A23 If I did not want to participate in this study, I could refuse to sign the consent form

A24 My family was not offered any alternatives besides involvement in this research study

QulC, Quality of Informed Consent.

aDenotes correct response.

subscale was examined using mean scores for individual items. The mean scores were compared among all independent variables using PROC GENMOD as previously described.

\section{RESULTS}

A total of 392 families were considered for inclusion in the study. Two families were excluded because the consenting parents no longer had custody of the probands, one family was excluded because the proband was deceased, and 11 families were excluded because a current, valid address could not be obtained. Of the 378 eligible families, 2 declined participation and 188 completed the surveys, yielding a response rate of
Agree (\%) Disagree (\%) Unsure (\%)

$\begin{array}{ccc}98.4^{\mathrm{a}} & 0 & 1.6 \\ 86.2^{\mathrm{a}} & 1.2 & 12.6 \\ 51.4^{\mathrm{a}} & 8.3 & 40.3 \\ 43.1 & 33.9^{\mathrm{a}} & 23.3 \\ 81.4^{\mathrm{a}} & 3.2 & 15.4 \\ 41.9 & 41.5^{\mathrm{a}} & 16.6\end{array}$

$\begin{array}{lll}86.6^{\mathrm{a}} & 1.6 & 11.8\end{array}$

$34.9 \quad 44.4^{a} \quad 20.6$

$\begin{array}{lll}42.9^{\mathrm{a}} & 9.1 & 48.0\end{array}$

$63.1 \quad 22.2^{\mathrm{a}} \quad 14.7$

$\begin{array}{lll}94.4^{\mathrm{a}} & 2.0 & 3.6\end{array}$

$\begin{array}{lll}37.8^{\text {a }} & 10.8 & 51.4\end{array}$

$\begin{array}{lll}87.3 & 6.7^{\mathrm{a}} & 6.0\end{array}$

$\begin{array}{lll}92.5^{\mathrm{a}} & 2.4 & 5.2\end{array}$

$\begin{array}{lll}40.5^{\mathrm{a}} & 36.1 & 23.4\end{array}$

$\begin{array}{lll}90.1^{\text {a }} & 2.4 & 17.5\end{array}$

$\begin{array}{lll}32.1 & 29.0^{a} & 38.9\end{array}$

$\begin{array}{lll}54.4^{\mathrm{a}} & 2.0 & 43.6\end{array}$

$71.0^{\mathrm{a}} \quad 0$

29.0

$\begin{array}{lll}86.1^{\mathrm{a}} & 2.0 & 11.9\end{array}$

$\begin{array}{lll}34.5^{\mathrm{a}} & 8.7 & 56.8\end{array}$

$\begin{array}{lll}11.5 & 62.8^{\mathrm{a}} & 25.7\end{array}$

$\begin{array}{lll}94.1^{\mathrm{a}} & 0.8 & 5.1\end{array}$

$\begin{array}{lll}13.1 & 68.8^{\mathrm{a}} & 18.2\end{array}$

$50 \%$. These 188 families represented a total of 287 individuals, of which 252 (88\%) completed the QuIC questionnaires. The remaining individuals stated that they were not present during the informed consent process for the LVOT study; therefore, they were not eligible to complete the questionnaires.

The characteristics of parents who participated in this study are presented in Table 3 . The majority of participants were female $(67 \%)$, white $(94 \%)$, college educated $(73 \%)$, and mothers of the proband $(63 \%)$. Nearly $70 \%$ were employed or selfemployed, and $13 \%$ were employed in the health or science field. Approximately $20 \%$ of the parents indicated that they or their child had participated in a prior research study. 
Table 2 QuIC assessment part B scores

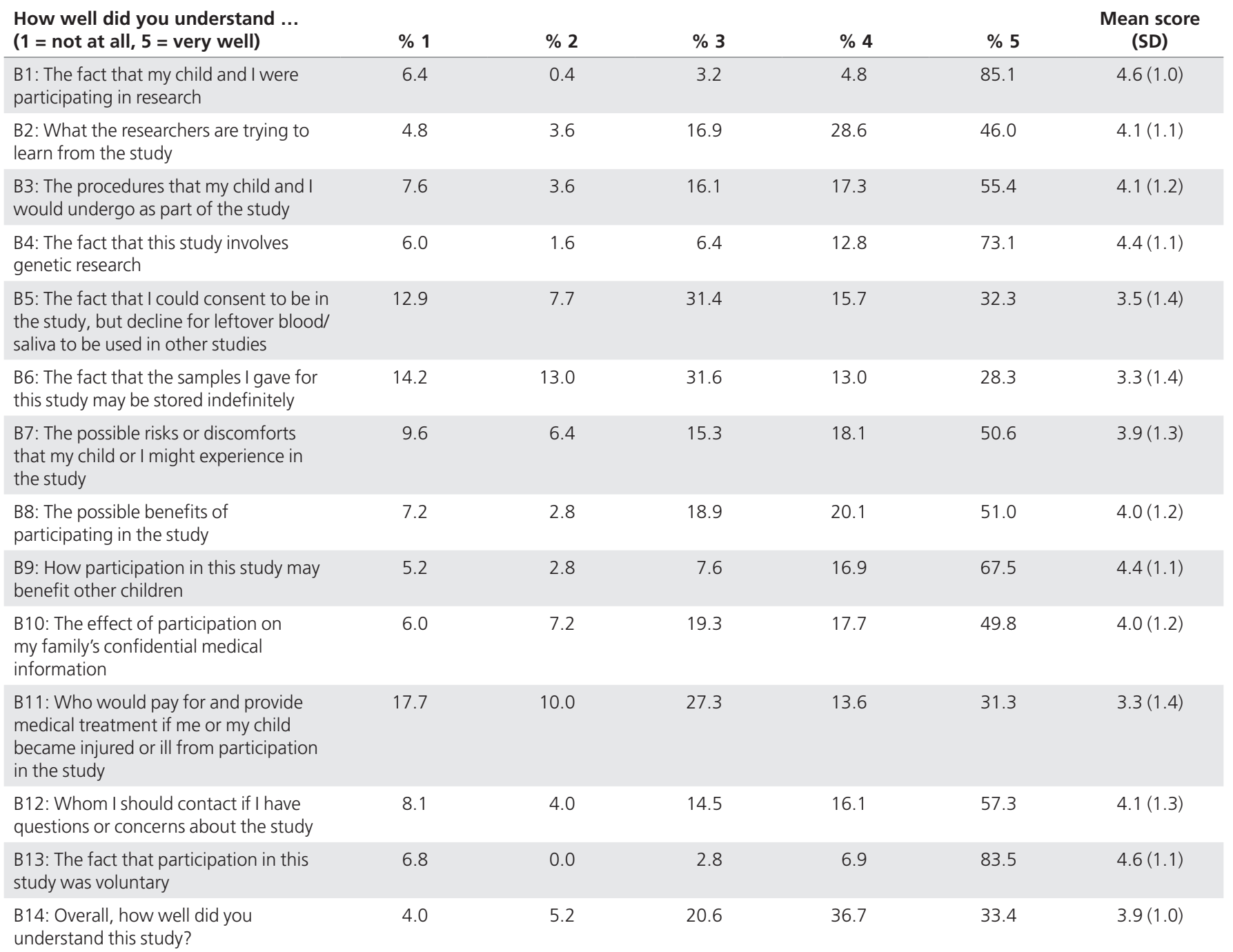

QuIC, Quality of Informed Consent.

The average age of probands at the time of consent for the LVOT study was $7.5 \pm 6.0$ years. The mean number of years since enrollment in the LVOT study was $3.1 \pm 1.4$ years. In most cases (52\%), the mother was the primary medical caretaker of the proband and both parents were usually involved in medical decision making (76\%). Comparison of demographics and proband characteristics between respondents and nonrespondents did not show any statistical differences.

The proportion of parent responses for each question and the mean score for each item of the QuIC assessment is presented in Table 1. More than $90 \%$ of participants correctly answered statements on consent for research participation (A1), use of family medical history (A11), no direct benefit (A14), purpose of research to understand cause of CVMs (A16), and ability to refuse participation (A24). Conversely, $<40 \%$ of participants correctly answered statements about use of leftover samples (A4), main study purpose is to find out how to treat my child (A6), indefinite storage of samples (A12), risks and harms
(A13), receipt of research results (A17), and payment of care due to injury from research (A21). The consent form language corresponding to the items with lower understanding can be found in Supplementary Table S1 online.

Multivariate analyses revealed some associations between parent or proband characteristics and individual QuIC part A items (Table 4). Parents aged $\leq 40$ years were less likely to respond correctly to items A4 (use of leftover samples) and A20 (who to contact with questions) than parents aged 40 years and older. Male participants were less likely to respond correctly to A22 (ability to withdraw participation) as compared with female participants. Marital status was significantly associated with correctly answering items A6 (main study purpose is to find out how to treat my child) and A8 (diagnosing CVMs in family members), with married parents more likely to respond correctly to each question. Medical decision making by both the parents was associated with correctly answering items related to the return of research results (items A4 and A17). 
Table 3 Demographic characteristics of KAIC study participants

\begin{tabular}{|c|c|}
\hline & Participants \\
\hline Age $(N=252)$, mean $(S D)$ & $39.5(8.5)$ \\
\hline \multicolumn{2}{|l|}{ Gender $(N=252), \%$} \\
\hline Male & 32.5 \\
\hline Female & 67.5 \\
\hline \multicolumn{2}{|l|}{ Race/ethnicity $(N=252), \%$} \\
\hline Non-Hispanic white & 94.1 \\
\hline Other/unknown & 5.9 \\
\hline \multicolumn{2}{|l|}{ Education $(N=250), \%$} \\
\hline$<\mathrm{HS}$ & 3.2 \\
\hline HS graduate or GED & 23.2 \\
\hline Some college or technical school & 32.0 \\
\hline College graduate or more & 41.6 \\
\hline \multicolumn{2}{|l|}{ Marital status $(N=250), \%$} \\
\hline Married & 82.8 \\
\hline Other & 17.2 \\
\hline \multicolumn{2}{|l|}{ Household income $(N=241), \%$} \\
\hline$<\$ 20,000$ & 14.1 \\
\hline$\$ 20,000-\$ 34,999$ & 10.4 \\
\hline$\$ 35,000-\$ 49,999$ & 13.3 \\
\hline$\$ 50,000-\$ 74,999$ & 22.8 \\
\hline$\$ 75,000$ or more & 39.4 \\
\hline \multicolumn{2}{|l|}{ Employment $(N=249), \%$} \\
\hline Employed/self-employed & 69.1 \\
\hline Homemaker & 15.3 \\
\hline Other & 15.6 \\
\hline \multicolumn{2}{|c|}{ Health/science occupation ( $N=247), \%$} \\
\hline Yes & 12.6 \\
\hline No & 87.4 \\
\hline \multicolumn{2}{|l|}{ Relationship to proband $(N=252), \%$} \\
\hline Mother & 63.4 \\
\hline Father & 35.9 \\
\hline Other & 0.7 \\
\hline \multicolumn{2}{|c|}{ Previous research participation ( $N=249), \%$} \\
\hline Yes & 18.9 \\
\hline No & 72.7 \\
\hline Don't know & 8.4 \\
\hline
\end{tabular}

GED, General Education Development certificate; HS, high school; KAIC, Knowledge, Attitudes and Informed Consent.

Conversely, medical decision making by both the parents was inversely associated with correct responses for items describing the indefinite storage of samples (items A9 and A12). As compared with those who had participated in research studies other than the LVOT study, individuals who had not participated in other studies and those who were not sure whether they had participated in other studies were less likely to respond correctly to A18 (anonymous data sharing with the NIH). Parents with higher incomes were less likely to respond correctly to item A21 (payment of care due to injury from research) as compared with participants with incomes $<\$ 35,000$. As compared with participants who consented for the LVOT study 4 or more years ago, participants who consented $<2$ years ago were more likely to respond correctly to A21.

The results for the QuIC subjective subscale are presented in Table 2. Overall, participants felt that they understood that they were participating in research (4.6), that the study involved genetic research (4.4), and that participation in the study was voluntary (4.6). Participants seemed less certain about the risks of study participation (3.9), that their samples would be stored indefinitely (3.3), and that they could decline for their samples to be used in other studies (3.3).

The proportion of individuals who answered questions correctly in QuIC part A items was compared with how well the individual thought they understood the item in QuIC part B. Low concordance (proportion answering incorrectly who thought they understood the question) was noted for A13/B7 (risks and harms; 7\%), A4/B5 (use of leftover samples; 34\%), A21/B11 (payment of care due to injury from research; 35\%), and A12/B6 (indefinite storage of samples; 38\%).

\section{DISCUSSION}

In this study of informed consent understanding, we found that parents often overestimated the personal benefit their child and/or family would receive from participation in a genetic study and undervalued the risks associated with study participation. This supports previous studies of informed consent understanding for adults consenting to participate in research studies. ${ }^{12-26}$ However, our study is the first to measure actual and perceived understanding of informed consent for parents who gave permission for their children to participate in a biobanking study. More than half of the parents were uncertain or responded incorrectly to the main questions of the study, including those regarding the use and storage of samples and the handling of results from the study. This is consistent with prior studies of adult biobanking participants. Ormond et al. ${ }^{13}$ demonstrated that nearly half of the subjects enrolled in a biobanking study were unaware that their DNA would be stored at all, a finding that this study confirmed. It is possible that participants may not understand the connection between the samples they provide (blood or saliva) and the storage of DNA. It is also possible that participants were unable to recall the procedures that they learned during the informed consent process, even though time since consent for the LVOT study was not associated with knowledge. Nevertheless, the core concept of biobanking consent is DNA storage and to have so few parents understand that concept is cause for significant concern.

In this study, questions related to research procedures, the return of research results, and the use of leftover samples were more likely to be answered correctly by parents who indicated that both the mother and the father were involved with medical decision making. Dual-parent responsibility for medical decision making may be associated with an increased 
Table 4 Independent correlates of correctly answering selected QuIC assessment part A items

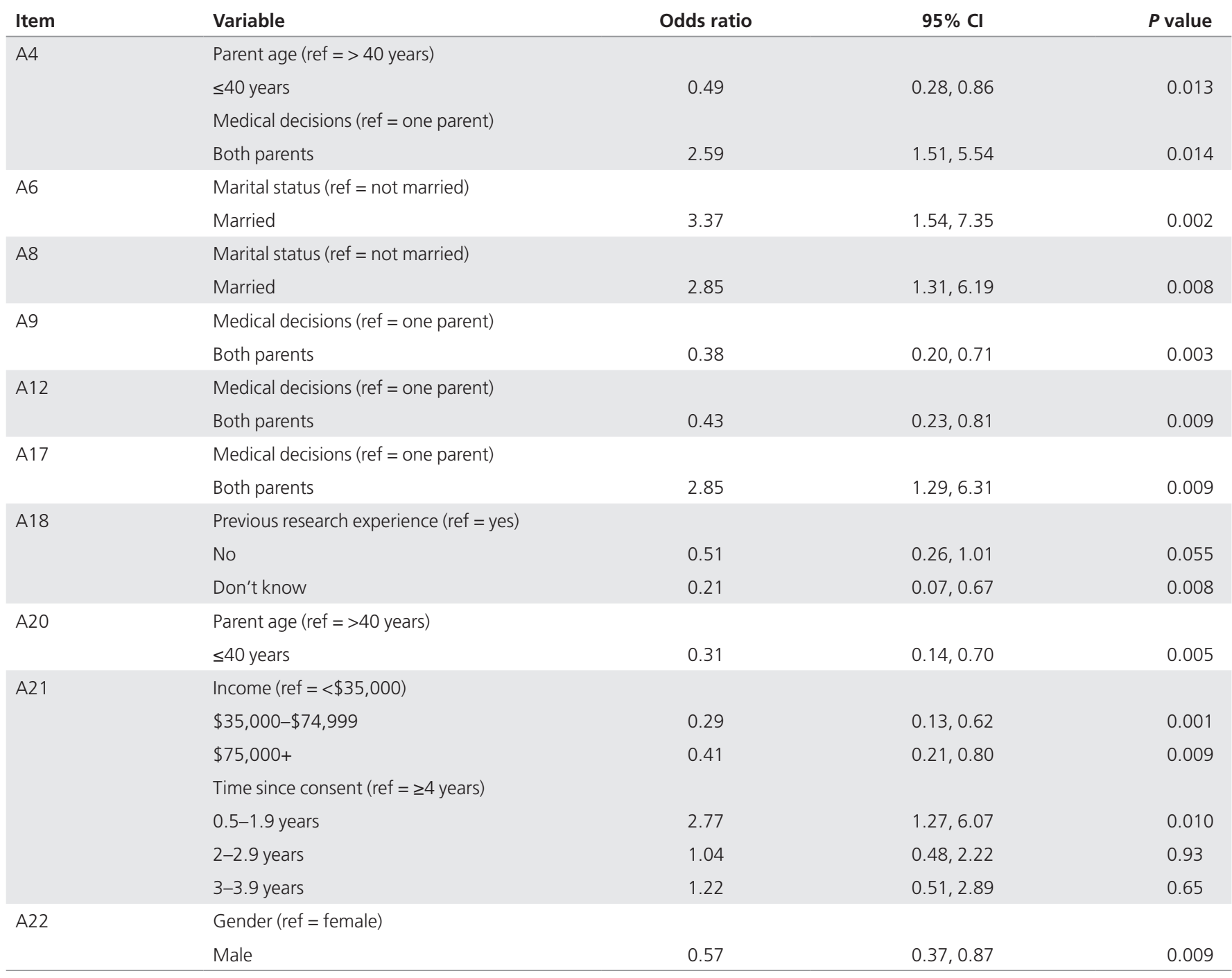

$\mathrm{Cl}$, confidence interval; QulC, Quality of Informed Consent.

understanding of study procedures due to the added support of having both the parents involved in the consent process. This, in turn, could allow the parents to follow more closely during the consent procedure, ask more questions of research staff, and share information with each other after the informed consent procedure. Similarly, participants who were married were more likely to correctly answer questions about the study's purpose. Although this study does not examine differences in one- versus two-parent households, there is evidence in the diabetes literature that family and parenting stress is higher among single parents. ${ }^{27,28}$ Higher stress is a potential impediment to parents' ability to learn illness management skills for their children. ${ }^{27}$ Of interest, the two questions regarding the indefinite storage of DNA were less likely to be answered correctly by parents in households where both the mother and the father participated in decision making. We hypothesize that participants related the questions about indefinite storage of samples (A9 and A12) to the question regarding the use of leftover samples by other researchers (A4) and responded similarly to these items. This emphasizes the need for clear consent form language, verbal explanation, and knowledge assessment when administering consent for biobanking so that potential participants understand the difference between indefinite storage and the use of their samples in future research. Brisson et al. ${ }^{6}$ recommend using a separate document to explain procedures and obtain consent for the biobanking part of a study to clarify the possible uses of stored samples and provide subjects with an opportunity to decline.

Given that the parents in this study had given consent for their children to participate, it is not surprising that they deemed the study to be relatively risk free. More than $80 \%$ agreed that there were no risks of harm to themselves or their children while participating in the study even though there was a blood-draw involved, and most were unsure of who would pay for injuries. This is consistent with previous studies that show that consenting adults and parents consenting 
for their children minimize the risks of research participation. ${ }^{29,30}$ Our study also noted that these questions were frequently incorrectly answered even though the parents felt that they had a good understanding. We speculate that the required informed consent template originally created for interventional studies regarding risks, harms, and payment for injuries does not transfer well to biobanking studies, resulting in confusion. Study participants who reported income in the highest two categories were less likely to respond correctly to the item about payment for injuries sustained because of the study as compared with participants in the lowest category of income $(<\$ 35,000)$. We can only speculate that parents with lower incomes may be more concerned with paying for additional medical care because their children are uninsured or underinsured. Not surprisingly, shorter length of enrollment in the study was positively associated with answering this question correctly. More recent exposure to specific study details such as payment for injury may increase the ability of study participants to recall this information.

Parents in this study overestimated their understanding. We found discrepancies in the items that were answered correctly on the objective subscale versus what parents thought they understood on the subjective subscale. For example, there was only $33.7 \%$ concordance for questions A4 and B5 relating to the indefinite storage of blood/saliva or tissue samples. The Marshfield and Nugene studies demonstrated discrepancies between objective and subjective scores on the QuIC assessment. ${ }^{13,14}$ Although the questions in this study are slightly different from those of the previously mentioned studies, it is apparent from these combined results that biobanking participants appear to think that they understand more than they do. Future research should include assessments of actual and perceived understanding immediately following consent to confirm these results.

When the original LVOT study was conceived, it was not routine to return genetic results to individuals or their families. The advent of massively parallel sequencing and the ability to identify many genetic changes has recently changed the landscape of reporting research results, particularly for "incidental findings." Multiple studies have shown that research participants want to receive results from the genetic research studies in which they participate, including results on children. ${ }^{31}$ Our findings give some support for this. Even though the consent form stated that results would not be returned, the majority of respondents were expecting return of results or were not certain if results would be returned.

It is important to note the limitations of this study. The participants (parents of children in the LVOT study) were largely white, more educated, and more affluent than most families of children treated for other illnesses; therefore, these finding may not be applicable to families enrolling in biobanks for other childhood diseases. It is also important to note that our sample size was likely to demonstrate statistical significance only for medium-to-large differences in understanding; however, small differences are likely less clinically relevant.
In conclusion, our study adds to the wealth of research demonstrating that informed consent understanding is inadequate in a variety of populations. This study also adds a concerning dimension that many parents did not understand that DNA would be stored in a biobanking study. Interventions to improve understanding, including visual aids and video consenting, provide promising results, but no recent clinical trials demonstrating effectiveness for biobanking consent have been published, and there is currently no push to adopt these techniques widely. ${ }^{32-39}$ To provide individuals and families with adequate knowledge to participate in genetic research, informed consent delivery must improve as the demand for genomic data increases. The focus of researchers should now shift to how to improve the informed consent process through alternative methods of consent delivery.

\section{SUPPLEMENTARY MATERIAL}

Supplementary material is linked to the online version of the paper at http://www.nature.com/gim

\section{ACKNOWLEDGMENTS}

This study was supported by the Ohio State University Graduate School's Alumni Grants for Graduate Research and Scholarship, Nationwide Children's Hospital, and NIH R01HL090506, K12HD43372, and K23HL70823.

\section{DISCLOSURE}

The authors declare no conflict of interest.

\section{REFERENCES}

1. Matsui K, Lie RK, Kita Y. Two methods of obtaining informed consent in a genetic epidemiological study: effects on understanding. J Empir Res Hum Res Ethics 2007:2(3):39-48.

2. Kaufman D, Geller G, Leroy L, Murphy J, Scott J, Hudson K. Ethical implications of including children in a large biobank for genetic-epidemiologic research: a qualitative study of public opinion. Am J Med Genet C Semin Med Genet 2008;148C:31-39.

3. Haga SB, Beskow LM. Ethical, legal, and social implications of biobanks for genetics research. Adv Genet 2008;60:505-544.

4. Dixon-Woods M, Ashcroft RE, Jackson CJ, et al. Beyond "misunderstanding": written information and decisions about taking part in a genetic epidemiology study. Soc Sci Med 2007;65:2212-2222.

5. Jenkins MM, Rasmussen SA, Moore CA, Honein MA. Ethical issues raised by incorporation of genetics into the National Birth Defects Prevention Study. Am J Med Genet C Semin Med Genet 2008;148C:40-46.

6. Brisson AR, Matsui D, Rieder MJ, Fraser DD. Translational research in pediatrics: tissue sampling and biobanking. Pediatrics 2012;129:153-162.

7. Wolf SM, Crock BN, Van Ness B, et al. Managing incidental findings and research results in genomic research involving biobanks and archived data sets. Genet Med 2012;14:361-384.

8. Brothers KB. Biobanking in pediatrics: the human nonsubjects approach. Per Med 2011;8:79.

9. Helft PR, Champion VL, Eckles R, Johnson CS, Meslin EM. Cancer patients' attitudes toward future research uses of stored human biological materials. $J$ Empir Res Hum Res Ethics 2007;2:15-22.

10. Lockhart NC, Yassin R, Weil CJ, Compton CC. Intersection of biobanking and clinical care: should discrepant diagnoses and pathological findings be returned to research participants? Genet Med 2012;14:417-423.

11. Ballard HO, Shook LA, Desai NS, Anand KJ. Neonatal research and the validity of informed consent obtained in the perinatal period. J Perinatol 2004;24:409415.

12. Joffe S, Cook EF, Cleary PD, Clark JW, Weeks JC. Quality of informed consent: a new measure of understanding among research subjects. J Nat/ Cancer Inst 2001;93:139-147. 
13. Ormond KE, Cirino AL, Helenowski IB, Chisholm RL, Wolf WA. Assessing the understanding of biobank participants. Am J Med Genet A 2009;149A:188198.

14. McCarty CA, Nair A, Austin DM, Giampietro PF. Informed consent and subject motivation to participate in a large, population-based genomics study: the Marshfield Clinic Personalized Medicine Research Project. Community Genet 2007:10:2-9.

15. Greenley RN, Drotar D, Zyzanski SJ, Kodish E. Stability of parental understanding of random assignment in childhood leukemia trials: an empirical examination of informed consent. J Clin Oncol 2006;24:891-897.

16. Mortensen MG, Kiyak HA, Omnell L. Patient and parent understanding of informed consent in orthodontics. Am J Orthod Dentofacial Orthop 2003;124:541-550.

17. Glock RS, Goldim JR. Informed consent in gerontology. Eubios J Asian Int Bioeth 2003;13:6-8

18. Kaewpoonsri N, Okanurak K, Kitayaporn D, Kaewkungwal J, Vijaykadga S, Thamaree $S$. Factors related to volunteer comprehension of informed consent for a clinical trial. Southeast Asian J Trop Med Public Health 2006;37:996-1004.

19. Appelbaum PS, Lidz CW, Grisso T. Therapeutic misconception in clinical research: frequency and risk factors. IRB 2004;26:1-8.

20. Criscione LG, Sugarman J, Sanders L, Pisetsky DS, St Clair EW. Informed consent in a clinical trial of a novel treatment for rheumatoid arthritis. Arthritis Rheum 2003:49:361-367.

21. Larobina ME, Merry CJ, Negri JC, Pick AW. Is informed consent in cardiac surgery and percutaneous coronary intervention achievable? ANZ I Surg 2007;77:530-534.

22. Whittle J, Conigliaro J, Good CB, Kelley ME, Skanderson M. Understanding of the benefits of coronary revascularization procedures among patients who are offered such procedures. Am Heart J 2007;154:662-668.

23. Beskow LM, Dean E. Informed consent for biorepositories: assessing prospective participants' understanding and opinions. Cancer Epidemiol Biomarkers Prev 2008;17:1440-1451.

24. Cox AC, Fallowfield L, Jenkins VA. Communication and informed consent in phase 1 trials: a review of the literature. Support Care Cancer 2006;14:303309.

25. Dunn LB, Palmer BW, Keehan M, Jeste DV, Appelbaum PS. Assessment of therapeutic misconception in older schizophrenia patients with a brief instrument. Am J Psychiatry 2006;163:500-506.

26. Robinson C, Thompson SJ, Woolhead C. Multiple pathways used for the targeting of thylakoid proteins in chloroplasts. Traffic 2001;2:245-251.
27. Streisand R, Swift E, Wickmark T, Chen R, Holmes CS. Pediatric parenting stress among parents of children with type 1 diabetes: the role of self-efficacy, responsibility, and fear. J Pediatr Psychol 2005;30:513-521.

28. Thompson SJ, Auslander WF, White NH. Comparison of single-mother and twoparent families on metabolic control of children with diabetes. Diabetes Care 2001;24:234-238.

29. Varma S, Jenkins T, Wendler D. How do children and parents make decisions about pediatric clinical research? J Pediatr Hematol Oncol 2008;30:823828.

30. Wendler D, Jenkins T. Children's and their parents' views on facing research risks for the benefit of others. Arch Pediatr Adolesc Med 2008;162:9-14.

31. Harris ED, Ziniel SI, Amatruda JG, et al. The beliefs, motivations, and expectations of parents who have enrolled their children in a genetic biorepository. Genet Med 2012;14:330-337.

32. Agre P, Rapkin B. Improving informed consent: a comparison of four consent tools. IRB 2003;25:1-7.

33. Campbell FA, Goldman BD, Boccia ML, Skinner M. The effect of format modifications and reading comprehension on recall of informed consent information by low-income parents: a comparison of print, video, and computer-based presentations. Patient Educ Couns 2004;53:205-216.

34. Dunn LB, Lindamer LA, Palmer BW, Schneiderman LJ, Jeste DV. Enhancing comprehension of consent for research in older patients with psychosis: a randomized study of a novel consent procedure. Am J Psychiatry 2001;158:1911-1913.

35. Eggers C, Obliers R, Koerfer A, et al. A multimedia tool for the informed consent of patients prior to gastric banding. Obesity (Silver Spring) 2007; 15:2866-2873.

36. Migden M, Chavez-Frazier A, Nguyen T. The use of high definition video modules for delivery of informed consent and wound care education in the Mohs Surgery Unit. Semin Cutan Med Surg 2008;27:89-93.

37. Nwomeh BC, Hayes J, Caniano DA, Upperman JS, Kelleher KJ. A parental educational intervention to facilitate informed consent for emergency operations in children. J Surg Res 2008;152:258-263.

38. Steffenino G, Viada E, Marengo B, Canale R; Nursing and the Medical Staff of the Cardiac Catheterization Unit. Effectiveness of video-based patient information before percutaneous cardiac interventions. J Cardiovasc Med (Hagerstown) 2007;8:348-353.

39. Wirshing DA, Sergi MJ, Mintz J. A videotape intervention to enhance the informed consent process for medical and psychiatric treatment research. Am J Psychiatry 2005;162:186-188 